\title{
A DOCÊNCIA UNIVERSITÁRIA E O CICLO DE VIDA PROFISSIONAL DOCENTE: UM OLHAR SOBRE AS PESQUISAS BRASILEIRAS
}

\author{
Solange Cardoso' \\ Kátia Augusta Curado Pinheiro Cordeiro da Silva
}

\begin{abstract}
RESUMO: Esse estudo do tipo estado do conhecimento tem como objetivo situar, conhecer e compreender a abordagem das pesquisas brasileiras sobre o ciclo de vida profissional docente no Ensino Superior, bem como averiguar os avanços e apontar possíveis lacunas. O levantamento foi realizado nas bases de dados da ANPEd e CAPES, reconhecidas como importantes meios de divulgação das pesquisas na área da educação. O estudo foi desenvolvido por meio digital, no período de uma década, 2006 a 2016. Os dados revelam carência expressiva de pesquisas e também, apresentaram lacunas acerca da presente temática, sugerindo investigações futuras a partir de diversas categorias de estudo. A pesquisa possibilitou compreender novas formas de explicar o desenvolvimento da vida profissional, destaca-se a existência de um "ciclo" que acontece de forma individual e, ao mesmo tempo, coletivo - para cada grupo de professores. Para compreendê-lo de forma abrangente e significativa, torna-se necessário considerar que existem Linhas de Força que atuam ao longo da trajetória docente, orientando determinadas escolhas, certos relacionamentos e modos diferenciados de agir. $E$ ainda que há um ciclo de vida profissional docente que perpassa pelas marcas do ensino superior somadas as concepções de docência trazidas de forma individual por cada professor e que cooptam uma docência técnica e interpessoal.
\end{abstract}

Palavras-Chave: Ciclo de Vida; Profissional Docente; Ensino Superior; Estado do Conhecimento.

\section{Introdução}

O campo da formação de professores, com diversas categorias de estudos, tais como desenvolvimento profissional docente; identidade; perspectivas de formação; profissionalização; avaliação do docente; trabalho docente; dentre outros, perpassa as nossas reflexões e inquietações sobre a trajetória profissional docente.

Partimos da premissa de que há uma complexidade sublinhada em todos os períodos da vida profissional dos professores, desde a chegada aos anos iniciais na docência - no movimento que se faz no decorrer desse percurso - e nos anos finais e de encerramento da docência. Ao mesmo tempo, nos questionamos: será que os professores vivenciam momentos comuns na vida profissional? Há um "ciclo" de vida profissional docente? A vida profissional docente é marcada apenas por vivências singulares? Por que há professores já desmotivados no início da carreira? E por que há professores no final da carreira ainda motivados? Podemos dizer que a vida profissional docente é assinalada ou dividida por fases, etapas ou estágios?

\footnotetext{
${ }^{1}$ Doutoranda no Programa de Pós Graduação em Educação - UnB; Bolsista de Doutorado (DS/CAPES). Contato: solangecardoso1908@gmail.com

2 Professora Associada da Universidade de Brasília (UnB). Contato: katiacurado@unb.br
} 
- Revista de Iniciação à Docência, v. 5, n. 1, 2020 -

Dossiê Temático: Docência Universitária: contribuições da pesquisa Publicação: maio, 2020 - ISSN 2525-4332

A partir desses questionamentos, sentimos a necessidade de nos aproximarmos da temática "ciclo de vida profissional docente" a fim de compreendermos como essa temática envolve e informa sobre a formação e atuação docente. Assim, trazemos como objetivo para esse estudo a intenção de situar, conhecer e compreender como as pesquisas brasileiras têm abordado essa temática no campo do Ensino Superior, além de averiguar os avanços e apontar possíveis carências e lacunas. Tal proposta se justifica pela necessidade de encontrarmos referências que apresentem investigações a partir da realidade dos professores brasileiros, pois o trabalho produzido por Huberman (2000) intitulado Ciclo de Vida dos Professores - apontado como a principal referência sobre a temática - foi desenvolvido em realidade francesa, a qual difere significativamente do cenário brasileiro. Considerando a relevância e o reconhecimento internacional da pesquisa produzida por Huberman (2000), dialogaremos com suas contribuições ao longo desse trabalho.

Optamos por desenvolver um trabalho do tipo estado do conhecimento, o qual, segundo André (2009), propõe uma síntese integrativa da produção acadêmica em uma determinada área do conhecimento e em um determinado período temporal. Esse tipo de estudo tem sido muito útil ao revelar temáticas priorizadas pelos pesquisadores e por fornecer dados importantes para aperfeiçoar a pesquisa num determinado campo do saber. Romanowski e Ens (2006) complementam e apontam que essas pesquisas possibilitam "[...] uma visão geral do que vem sendo produzido na área e uma ordenação que permite aos interessados perceberem a evolução das pesquisas na área, bem como suas características e foco, além de identificar as lacunas ainda existentes [...]” (p. 41). Para as autoras, é importante que os estudos sejam convalidados, tais como as teses e dissertações resultantes de pesquisas analisadas por bancas; as publicações de periódicos de referência nacional e os trabalhos avaliados por comitês científicos, apresentados em congressos.

Nesse trabalho, o levantamento foi realizado em duas bases de dados, reconhecidas como importantes meios de divulgação das pesquisas na área da educação brasileira. Essa escolha se deu pela compreensão de que essas bases atendem às orientações das referidas autoras, no que se refere a serem estudos convalidados por bancas ou comitês científicos. Assim, o presente estudo foi desenvolvido a partir dos trabalhos apresentados nas reuniões nacionais da Associação Nacional de Pós Graduação e Pesquisa em Educação (ANPEd) - mais especificamente, no Grupo de Trabalhos sobre Formação de Professores (GT 08) -, considerando também o banco de teses e dissertações da Coordenação de Aperfeiçoamento de Pessoal de Nível Superior (CAPES). O levantamento foi desenvolvido por meio digital, utilizando como descritores os termos "ciclo carreira docente"; "ciclo profissional docente"; "ciclo de vida dos professores"; "ciclo de vida profissional”. Após a localização de trabalhos que utilizaram esses descritores, foi realizada uma leitura nos resumos dos estudos para verificarmos se a temática agregava no mesmo trabalho os dois 
- Revista de Iniciação à Docência, v. 5, n. 1, 2020 -

Dossiê Temático: Docência Universitária: contribuições da pesquisa

Publicação: maio, 2020 - ISSN 2525-4332

termos que nos propusemos investigar: ciclo de vida profissional docente (e afins) e ensino superior.

\section{O levantamento sobre ciclo de vida profissional docente nas bases de dados: ANPEd e CAPES}

Considerando a necessidade de encontrarmos fontes brasileiras que nos aproximassem da temática que envolve o Ciclo de Vida Profissional Docente, apresentamos os resultados dos levantamentos realizados no GT 8 da ANPEd e no banco de teses e dissertações da CAPES. A Tabela 1 apresenta o número de trabalhos selecionados e, também, o número de trabalhos com interface relacionada a temática do Grupo de Trabalhos sobre Formação de Professores (GT 08) da ANPEd.

Tabela 1 - Informativo sobre o número de trabalhos encontrados e com interface com o tema no Grupo de trabalhos sobre Formação de Professores (GT 08) da ANPEd.

\begin{tabular}{|c|c|c|}
\hline Reunião/Ano & $\begin{array}{l}\text { Número de trabalhos } \\
\text { encontrados }\end{array}$ & $\begin{array}{c}\text { Número de trabalhos com } \\
\text { interface com o tema }\end{array}$ \\
\hline $29^{a} / 2006$ & 29 & 0 \\
\hline $30 \mathrm{a} / 2007$ & 31 & 1 \\
\hline $31^{a} / 2008$ & 18 & 0 \\
\hline $32^{a} / 2009$ & 21 & 0 \\
\hline $33 \mathrm{a} / 2010$ & 21 & 0 \\
\hline $34^{a} / 2011$ & 22 & 0 \\
\hline 35 a $/ 2012$ & 22 & 0 \\
\hline $36^{a} / 2013$ & 18 & 0 \\
\hline $37^{a} / 2015$ & 36 & 0 \\
\hline $38^{a} / 2017$ & 24 & 0 \\
\hline TOTAL & 242 & 0 \\
\hline
\end{tabular}

Fonte: Dados organizados pelas autoras com base nos trabalhos do GT8 - ANPEd.

Podemos observar, a partir dos dados apresentados na Tabela 1, que o número de trabalhos com interface relacionada ao tema, no período que delimitamos, é inexpressivo $(0,41 \%)$. Dos 242 trabalhos encontrados apenas um apresentou como objeto de estudo e como proposta uma investigação sobre o ciclo de vida profissional docente. E esse trabalho foi realizado no ensino superior, atendendo assim as especificidades que propusemos para realizar tal investigação. A constatação de um número pouco expressivo nessa base de dados serve como um elemento motivador para investirmos na investigação dessa temática, pois o campo encontra-se carente de mais pesquisas. Essa constatação aponta ainda, segundo Romanowski e Ens (2006) que alguns temas são quase que totalmente silenciados em determinadas campos do conhecimento. Contudo, os 242 trabalhos encontrados, em sua maioria, fazem menção ao Ciclo de Vida Profissional dos Professores elaborado por Huberman, para situarem em seu estudo a etapa do ciclo que é investigada -, mas sem a pretensão de estudá-lo por completo. Observamos que nesses trabalhos há 
- Revista de Iniciação à Docência, v. 5, n. 1, 2020 -

Dossiê Temático: Docência Universitária: contribuições da pesquisa Publicação: maio, 2020 - ISSN 2525-4332

investigações sobre os professores iniciantes e a fase de entrada na docência; há também estudos com o foco nos professores no final da carreira docente; e, há ainda a escolha por outras etapas demarcadas para justificar a escolha por uma determinada fase.

Os trabalhos encontrados em nosso levantamento se reportam a cinco fases do Ciclo de Vida Profissional dos Professores, elaboradas por Huberman (2000), nos quais são apresentadas características presentes em cada uma das cinco fases, apontando que a carreira docente é marcada por particularidades inerentes à cada etapa. Para o autor, a carreira é um processo contínuo e não uma série sucessiva de acontecimentos, sendo marcada pela não uniformidade dos sentimentos vivenciados pelos professores nas etapas, pois suas definições apresentam um entendimento mais generalizante sobre elas. O autor aponta, ainda, o quanto é difícil estudar o ciclo de vida dos professores com a pretensão de extrair perfis-tipo, sequências e fases, pois integrar num mesmo grupo os indivíduos que parecem partilhar traços em comum é uma tarefa arriscada, uma vez que é preciso considerar as diferenças nos meios sociais. Diante disso, Huberman (2000) apresenta as características mais marcantes em cada uma das cinco etapas denominadas: 1) Tateamento; 2) Estabilização; 3) Diversificação e questionamento; 4) Serenidade, distanciamento afetivo e conservadorismo; 5) Desinvestimento.

Para o referido autor, a fase de entrada na carreira ou a fase do tateamento corresponde aos três primeiros anos da docência. Essa fase é caracterizada pela "sobrevivência” e pela “descoberta”. A "sobrevivência” relaciona-se com

[...] o "tatear constante, a preocupação consigo próprio, a distância entre os ideais e as realidades cotidianas da sala de aula, a fragmentação do trabalho, a dificuldade em fazer face, simultaneamente, à relação pedagógica e à transmissão de conhecimentos, a oscilação entre relações demasiado íntimas e demasiado distantes, dificuldades com alunos que criam problemas, com material didático inadequado etc. (HUBERMAN, 2000, p. 39).

O aspecto da "descoberta" relaciona-se ao entusiasmo do professor diante das novidades que vão sendo desvendadas, a cada dia em sua profissão, e que estão atreladas à experiência de se sentir responsável por uma turma ou por se sentir como um membro de um grupo.

A fase da estabilização corresponde ao período entre 4 a 6 anos de carreira, caracterizada pelo comprometimento definitivo na docência e, ainda, como uma fase de tomada de responsabilidades. Assim, se refere a uma escolha subjetiva de se comprometer definitivamente e de um ato administrativo que implica em uma nomeação oficial. Significa ainda ter o sentimento de pertença a um corpo profissional e, também, adquirir independência - com o sentido de libertação e emancipação -, pois os professores sentemse mais seguros para se afirmarem frente aos colegas mais experientes.

A fase da diversificação e a fase do questionamento ocorrem no mesmo período, qual seja, entre 7 a 25 anos de carreira. No entanto, a primeira fase é marcada pela quebra 
- Revista de Iniciação à Docência, v. 5, n. 1, 2020 -

Dossiê Temático: Docência Universitária: contribuições da pesquisa Publicação: maio, 2020 - ISSN 2525-4332

da rigidez pedagógica, momento em que o professor começa a fazer experimentações, ora pessoais - com o material didático -, ora com a forma de avaliar e organizar os alunos em sala e, até mesmo, no que se refere a elaboração da sequência do programa curricular. Antes dessa fase, o professor não se sente seguro para arriscar, pois o medo de errar e as incertezas o aprisionam em uma rigidez pedagógica. A segunda fase é caracterizada pelas dúvidas quanto à carreira e quanto à profissão. Envolve sintomas, tais como a sensação de rotina e monotonia associadas aos desencantos advindos dos fracassos das experiências ou das reformas estruturais e, até mesmo, uma crise existencial. Essa crise se refere a um balanço da vida, período em que o professor examina o que realizou até o momento; questiona se já alcançou os objetivos que tinha ao iniciar na docência; pensa na possibilidade de mudar de profissão, mas teme não dar conta de recomeçar com o tempo que lhe resta.

No período entre 25 a 35 anos de carreira ocorre a fase da serenidade $e$ distanciamento afetivo, sendo elas identificadas por características que vão ao encontro dos nomes que as definem. $\mathrm{Na}$ fase da serenidade os professores apresentam-se menos vulneráveis a avaliação de seus pares, dos alunos e até mesmo dos gestores. Demonstram que estão vivenciando a serenidade ao exporem de forma evidente que chegaram ao ponto de se aceitarem como são e não segundo a vontade dos outros. Não sentem a obrigação de ter que provar eficiência a si mesmo ou aos outros. Nesse mesmo período, observa-se, também, a fase do conservadorismo, marcada pelas lamentações frente à profissão. Os professores que passam por essa fase se queixam dos alunos indisciplinados e desmotivados; dos colegas mais jovens, os quais, segundo eles, são menos sérios e menos empenhados na profissão; também se queixam das políticas educacionais e da atitude negativa para com o ensino.

Por último, ocorre a fase do desinvestimento - entre 35 a 40 anos de docência -, período em que os professores se afastam da profissão e dedicam seu tempo mais a si próprios e aos interesses exteriores a escola. Nessa fase, buscam uma vida social com maior carga filosófica, demonstrando consciência acerca do fim da carreira. Embora seja comum que o desinvestimento ocorra no final do carreira, há estudos que demonstram que alguns professores antecipam essa fase - já no início ou no meio da carreira -, pois ao se verem desiludidos com seu trabalho docente e com as questões relativas à carreira, canalizam sua energia para outras dimensões de sua vida, porém, alguns não conseguem fazer esse movimento e desistem. No Brasil, a fase do desinvestimento tem ocorrido bem mais cedo. As más condições de trabalho, tais como os baixos salários; a dupla jornada de trabalho; a falta de recursos materiais nas escolas; infraestrutura precária; número alto de alunos por turma, são alguns dos elementos que contribuem para que os professores não invistam na carreira. Além disso, muitos professores, por não encontrarem nessa profissão o retorno que almejavam, desistem no início da carreira. 
No Quadro 1 é apresentada a síntese das fases da carreira, segundo as proposições de Huberman (2000).

Quadro 1 - Modelo síntese elaborado por Michael Huberman.

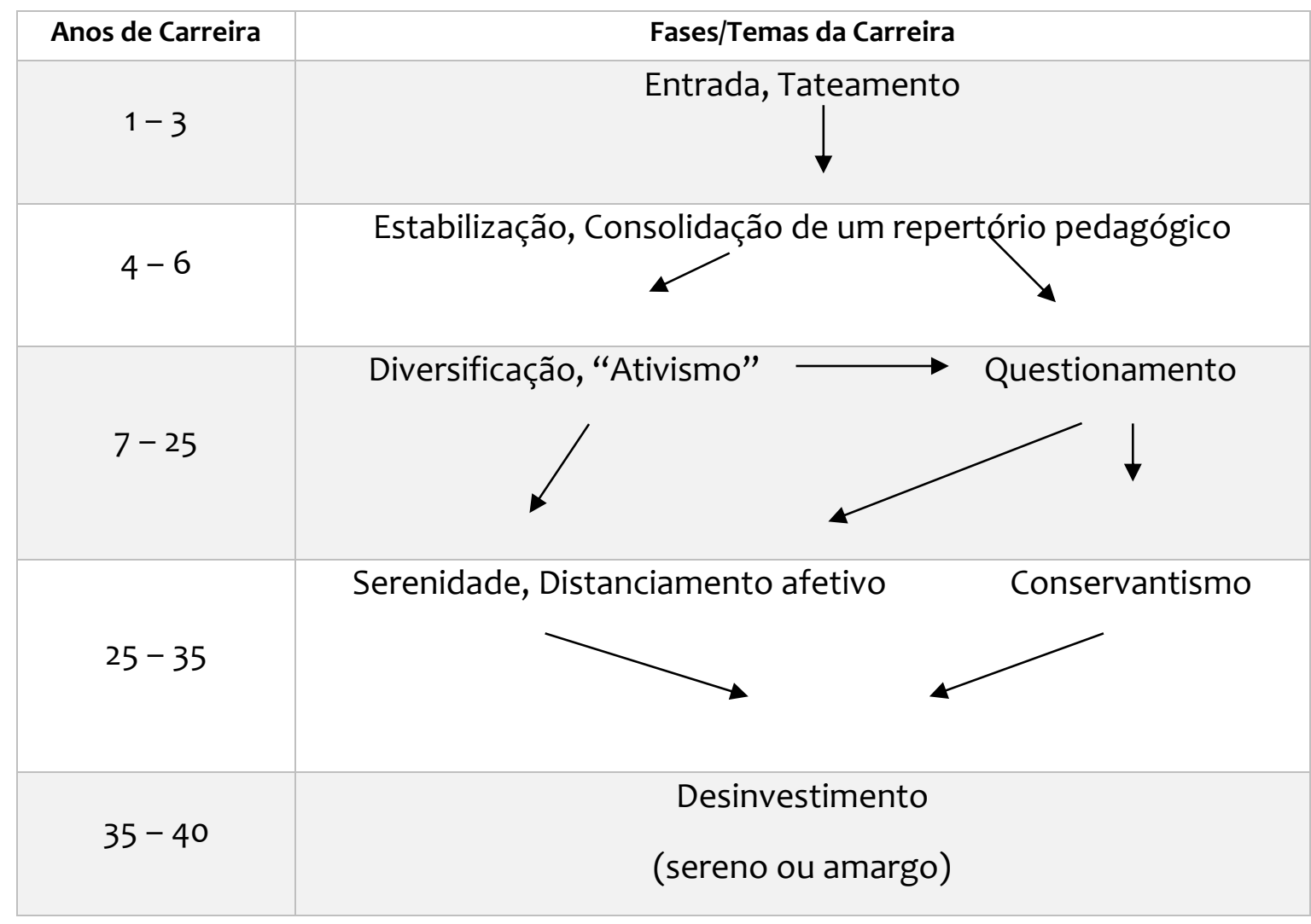

Fonte: Huberman (2000), adaptado pelas autoras.

O modelo síntese agrupa as principais tendências, em cada fase do ciclo de vida profissional. Também, aponta que até a fase da estabilização existe uma linha única e indica que, a partir dessa fase, há ramificações que ocorrem no meio da carreira, porém, na fase do desinvestimento, ocorre novamente uma linha única. Assim, há percursos que podem ser harmoniosos e percursos considerados problemáticos, conforme apresenta o Quadro 2.

Quadro 2 - Possíveis percursos no ciclo de vida profissional dos professores.

\begin{tabular}{|c|c|c|}
\hline Percurso Harmonioso & Percurso Problemático 1 & Percurso Problemático 2 \\
\hline Entrada & Entrada & Entrada \\
\hline Estabilização & Estabilização & Estabilização \\
\hline Diversificação & Questionamento & Questionamento \\
\hline Serenidade & Desinvestimento amargo & Conservantismo \\
\hline Desinvestimento sereno & & Desinvestimento amago \\
\hline
\end{tabular}

Fonte: Elaborado pelas autoras a partir da síntese de Huberman (2000). 
- Revista de Iniciação à Docência, v. 5, n. 1, 2020 -

Dossiê Temático: Docência Universitária: contribuições da pesquisa Publicação: maio, 2020 - ISSN 2525-4332

Huberman (2000) ressalta que além desses três possíveis percursos, há que se considerar que outros caminhos podem ser seguidos, dependendo das particularidades dos grupos de professores. Para o autor, pode acontecer o fato de muitos professores permanecerem por longos períodos na fase de entrada - em um processo de tateamento e exploração -, e demorarem a se estabilizar por fatores diversos, os quais podem ser de ordem psicológica, social ou devido às condições de trabalho na escola. Assim, para o autor, devem ser considerados todo o percurso dos professores e não apenas o momento atual, pois a carreira desses profissionais é sublinhada por diversas situações que afetam as trajetórias de suas vidas. Portanto, segundo ele, seria mais interessante identificar as subfamílias dos docentes e observar o percurso que cada um faz, em detrimento de apresentar uma caracterização genérica, pois essa não considera as singularidades essenciais dos grupos. Logo, para Huberman (2000) a vida profissional docente deve ser vista como um processo que se desenvolve continuamente e não como uma série de acontecimentos sobrepostos, pois "[...] para alguns, este processo pode ser linear, mas, para outros, há patamares, regressões, becos sem saída, momentos de arranque, descontinuidades [...]" (HUBERMAN, 2000, p. 38).

A partir da análise dos trabalhos encontrados no GT8 da ANPEd, evidenciamos que apenas um deles teve como proposta compreender o ciclo de vida profissional docente, por completo, seja buscando compreender todas as etapas que ele constitui - ou como ele é construído em outras realidades que não a francesa, tais como a de Huberman -, seja em outros segmentos de ensino, não somente o secundário, como também fez o referido autor. Trata-se do trabalho de Isaia, Bolzan e Giordani (2007)

Na Tabela 2, assim como realizado nos trabalhos da ANPEd, apresentamos o número de trabalhos identificados e, também, o número de trabalhos com interface com a temática proposta no Banco de Teses e Dissertações da CAPES.

Tabela 2 - Informativo sobre o número de trabalhos encontrados e com interface com o tema pesquisado no Banco de Teses e Dissertações da CAPES.

\section{Termo Chave}

Número de Trabalhos Encontrados
Número de Trabalhos com Interface com o Tema

\begin{tabular}{c|cc|}
\hline \begin{tabular}{c|c} 
"Ciclo carreira docente" \\
"Ciclo profissional docente"
\end{tabular} & 0 & 0 \\
"Ciclo de vida dos professores" & 1 & 0 \\
"Ciclo de vida profissional" & 6 & 1 \\
TOTAL & 20 & 1
\end{tabular}

Fonte: Dados organizados pelas autoras, com base nos trabalhos da CAPES 
- Revista de Iniciação à Docência, v. 5, n. 1, 2020 -

Dossiê Temático: Docência Universitária: contribuições da pesquisa

Publicação: maio, 2020 - ISSN 2525-4332

O levantamento realizado no Banco de Teses e Dissertações da CAPES, conforme os dados apresentados na Tabela 2, também aponta que há um inexpressivo número de trabalhos que abordam a temática. Também indica que no período de 10 anos de pesquisas, apenas um trabalho dos 27 encontrados teve como objeto de estudo o Ciclo de Vida Profissional. Considerando a escassez de trabalhos e a necessidade de se conhecer mais sobre essa temática - incluindo a importância de saber como ela se apresenta no cenário nacional, apontaremos as contribuições dessa pesquisa, as quais consideramos indicarem avanços relevantes para pesquisas futuras, independente do lócus, nível ou modalidades de ensino que o pesquisador se propor a realizar seu estudo.

\section{Avanços e contribuições das pesquisas brasileiras sobre Ciclo de Vida Profissional Docente}

No trabalho intitulado "Movimentos construtivos da docência superior: delineando possíveis ciclos de vida profissional", de autoria de Isaia, Bolzan e Giordani, publicado nos anais da $30^{\text {a }}$ Reunião Nacional da ANPEd no GT 8, no ano de 2007 , as autoras pesquisaram sobre os ciclos de vida profissional de docentes do ensino superior e realizaram a pesquisa com professores de licenciatura e de bacharelado da Universidade Federal de Santa Maria (UFSM), com o objetivo compreender como os professores universitários se constituem ao longo da trajetória docente e qual a pedagogia que os norteia. Para tal, consideraram as concepções de docência e o contexto institucional acadêmico no qual esses professores atuam. As autoras partiram das seguintes indagações: quais os movimentos construtivos à docência superior? Qual o delineamento possível de ciclos de vida profissional docente desses sujeitos? Na busca pelas respostas a tais questionamentos elas consideraram o tempo de experiência no magistério superior e classificaram esse percurso em: anos iniciais (0-5), anos intermediários (6-15) e anos finais (16 anos em diante). E a partir das narrativas buscaram descrever e interpretar os relatos escritos que os professores apresentaram sobre os acontecimentos vividos ao longo da carreira docente, bem como buscaram compreender como estes relatos repercutiram no movimento transformacional das concepções de docência que adotam.

A partir de 20 auto-reconstruções biográficas elas puderam evidenciar quais os movimentos os professores participantes percebem em suas trajetórias profissionais e assim esboçaram quatro etapas que contemplam os seguintes movimentos construtivos:

1- Preparação à carreira docente

2- Entrada efetiva no magistério superior

3- A marca da pós-graduação na docência superior

4- A consciência da docência

O primeiro movimento construtivo, Preparação à carreira docente, envolve experiências que precedem a entrada na carreira docente como as monitorias, cursos de pós-graduação, atuação como professor substituto e as influências familiares. Configura- 
- Revista de Iniciação à Docência, v. 5, n. 1, 2020 -

Dossiê Temático: Docência Universitária: contribuições da pesquisa Publicação: maio, 2020 - ISSN 2525-4332

se como um período de formação inicial para a futura carreira e um momento de contato com o trabalho docente e a dinâmica que o envolve.

O segundo movimento construtivo, Entrada efetiva no magistério superior, é marcado por percepções que envolvem a solidão pedagógica que é sentida pela falta de apoio institucional ao professor iniciante e também por parte dos colegas mais experientes. É marcado também pelo conhecimento pedagógico compartilhado que engloba as relações entre o domínio do saber fazer com o saber teórico e conceitual. Também a insegurança frente aos alunos ou à disciplina, que segundo as autoras é devido ao despreparo dos professores para a docência no ensino superior uma vez que não é contemplado nos currículos dos cursos de graduação e pós-graduação. Há ainda a percepção na centração do conteúdo específico, uma marca dos professores iniciantes que valorizam e se preocupam com os conhecimentos sobre os conteúdos a serem ensinados. E ainda o estranhamento à docência que decorre da falta de preparo para o ser professor no ensino superior, por considerarem que a formação inicial e o início da carreira são suficientes para assegurar um bom desempenho docente.

No que se refere ao terceiro movimento construtivo, A marca da pós-graduação na docência superior, a percepção dos professores considera que a titulação e a produção científico-acadêmica são critérios de seleção e progressão. Somado a isso a pós-graduação, os professores creditam a pós-graduação o movimento de expansão e aprofundamento dos conhecimentos, a possibilidade de se formarem pesquisadores e docentes no ensino superior.

E por último, o quarto movimento construtivo, A consciência da docência, traz a percepção de inacabamento na docência universitária, uma consciência que a docência é um processo construído ao longo da carreira.

Para as autoras Isaia, Bolzan e Giordani (2007) a docência envolve todas as atividades desenvolvidas pelos professores e também as atividades orientadas para a preparação de futuros profissionais. E essas atividades:

estão alicerçadas, não só em conhecimentos, saberes e fazeres, mas também em
relações interpessoais e vivências de cunho afetivo, valorativo e ético, o que indica
o fato da atividade docente não se esgotar na dimensão técnica, mas remeter ao
que de mais pessoal existe em cada professor. Dessa forma, a docência superior
apóia-se na dinâmica da interação/compartilhamento de diferentes processos que
respaldam o modo como os professores concebem o conhecer, o fazer, o ensinar,
e o aprender, bem como o significado e o sentido que dão a eles (ISAIA; BOLZAN;
GIORDANI 2007, p. 11).

Diante do exposto, podemos dizer que as referidas autoras elaboram um "novo ciclo de vida profissional docente" que perpassa pelas marcas do ensino superior somadas às concepções de docência apresentadas pelos professores participantes da pesquisa. $A$ partir das concepções trazidas de forma individual por cada professor, elas concluem que há um ciclo marcado por quatro movimentos singulares que cooptam uma docência técnica e interpessoal. 
- Revista de Iniciação à Docência, v. 5, n. 1, 2020 -

Dossiê Temático: Docência Universitária: contribuições da pesquisa Publicação: maio, 2020 - ISSN 2525-4332

Já no banco de teses e dissertações da CAPES localizamos um trabalho, sendo esse uma tese intitulada "O ciclo de vida profissional dos professores da Universidade Federal de Uberlândia: Trajetórias, Carreira e Trabalho no Instituto de Biologia", de autoria de Brito (2011). A tese traz contribuições relevantes que merecem ser consideradas para investigarmos sobre a temática ciclo de vida profissional docente. A autora, por meio de entrevistas temáticas ${ }^{3}$, apresenta a narrativa de cinco professores efetivos com tempos variados de atuação na docência do ensino superior federal.

Destacamos quatro contribuições que consideramos serem importantes em pesquisas futuras sobre a temática. A primeira, que ora julgamos ser a mais relevante e um avanço nas pesquisas que envolvem essa temática, diz respeito ao que a autora chama de Linhas de Força. Ela se reporta ao trabalho de Cavaco (1993), comungando com as ideias apresentadas por essa autora, ao destacar que no ciclo de vida profissional docente coexistem essas Linhas de Força - segundo elas, presentes o tempo todo em nossas vidas, por meio dos nos nossos afetos, em nossa vida social e nas experiências de toda natureza -, nos impondo escolhas e mudanças de comportamento. Brito (2011) sintetiza a definição feita por Cavaco (1993) e nos diz que as Linhas de Força são:

Expectativas pessoais e familiares relacionadas a oportunidades e a condições
institucionais; tensão e sentimentos que acompanham as primeiras experiências
profissionais, contribuindo para a elaboração com os alunos, com os colegas, com
o conhecimento e a própria profissão, dificuldades relativas à articulação com a
dimensão familiar e profissional; mudança de expectativas decorrentes de
alterações institucionais, podendo levar a maior investimento pessoal (BRITO,
2011, p. 282).

A partir da constatação da existência de "linhas de força" - presentes ao longo de todo processo de amadurecimento profissional, bem como na relação com os pares, com os alunos, com o conhecimento e com a própria profissão -, a autora ressalta que elas coexistem com todos os momentos de transição de uma fase para outra. Destaca, ainda, que existe um ciclo de carreira que acontece de forma individual e ao mesmo tempo coletivo - ou seja, cada professor vivencia e sente as fases da carreira de forma singular, a partir do seu contexto social e da sua singularidade -, contudo, há nessa trajetória pontos de intercessão pelos quais todos passarão, condição que torna o ciclo algo coletivo. Assim, Brito (2011) constrói o ciclo de vida profissional de cada professor/colaborador a partir de suas histórias, considerando o que cada um apresenta como etapas em sua trajetória. Para isso, ela provoca cada colaborador a pensar sobre as fases de sua vida na condição de professor universitário. Nessa provocação, ela percebe que, em alguns momentos, a trajetória como professor universitário se mistura com as experiências anteriores à docência no ensino superior. Assim, a autora identifica e constrói os ciclos individuais de

\footnotetext{
3 Segundo Delgado (2006), as entrevistas temáticas se referem a experiências e processos específicos vividos ou testemunhados por um dado grupo. Tais entrevistas podem se constituir em desdobramentos dos depoimentos de Histórias de Vida, ou compor um elenco específico vinculado a um projeto de pesquisa, por exemplo, uma dissertação ou tese.
} 
- Revista de Iniciação à Docência, v. 5, n. 1, 2020 -

Dossiê Temático: Docência Universitária: contribuições da pesquisa

Publicação: maio, 2020 - ISSN 2525-4332

cada professor a partir das fases que eles demarcam em seu ciclo. Para alguns professores, o ciclo tem duas fases, para outros três ou quatro fases. Como exemplo, apresentamos dois ciclos construídos pela referida autora. O ciclo do professor Marçal - com quatro fases - e o ciclo da professora Jacobucci - com duas fases, respectivamente nos Quadros 3 e 4.

Quadro 3 - Fases da vida profissional do Professor Marçal.

Início de carreira (com duração de dois anos) - mostrar o trabalho para os outros; conhecer o funcionamento da universidade; nas palavras do professor: "mostrar para que veio".

Término do doutorado (é iniciado outro tipo de vivência na universidade) - pesquisa; orientandos; expansão das atividades dentro e fora da universidade.

Diversificação e calmaria (fase do pós-doutorado) - para esse professor, essa fase é um momento importante de ganho de autoridade e concentração de esforços em torno do que de fato um doutor faz: orientação, aula, pesquisa, extensão e, ao mesmo tempo, um período de "águas calmas".

Assunção de cargos de esferas maiores na universidade (decorrência dos anos anteriores de trabalho junto à universidade) - acontece uma diminuição de produtividade de artigos científicos; de orientações; pois o tempo está tomado por cargos administrativos.

Fonte: Brito (2011).

Quadro 4 - Fases da vida profissional da Professora Jacobucci.

A primeira fase (antecede seu doutorado em Educação) - ligada a experiências anteriores à assunção ao cargo na Universidade Federal de Uberlândia. A marca dessa fase é a predominância da técnica no seu exercício docente.

A segunda fase (tem início após o envolvimento com o doutorado em Educação) - é uma fase de consolidação que perpassa a ação docente. Percebe que tem muito o que caminhar.

Fonte: Brito (2011).

Os quadros apresentados por Brito (2011) reforçam o que a autora diz sobre as singularidades das etapas, embora o lócus - Instituto de Biologia da Universidade Federal de Uberlândia e o cargo de professor universitário - sejam elementos comuns aos colaboradores da pesquisa, cada um constrói e vivencia o ciclo de vida profissional do seu modo, "[...] entremeadas por suas histórias de vida, pela história da universidade e das políticas públicas de educação [...]” (BRITO, 2011, p. 298).

A partir dos quadros individuais de todos os colaboradores da pesquisa, a autora elaborou um quadro síntese, no qual aponta os pontos de interseção existentes em cada fase do ciclo de vida profissional dos professores. Em sua análise, reforça que esses pontos comuns tornam o ciclo de característica coletiva, conforme apresentado no Quadro 5. 
- Revista de Iniciação à Docência, v. 5, n. 1, 2020 -

Dossiê Temático: Docência Universitária: contribuições da pesquisa

Publicação: maio, 2020 - ISSN 2525-4332

Quadro 5 - Quadro síntese sobre as fases de um ciclo de vida profissional.

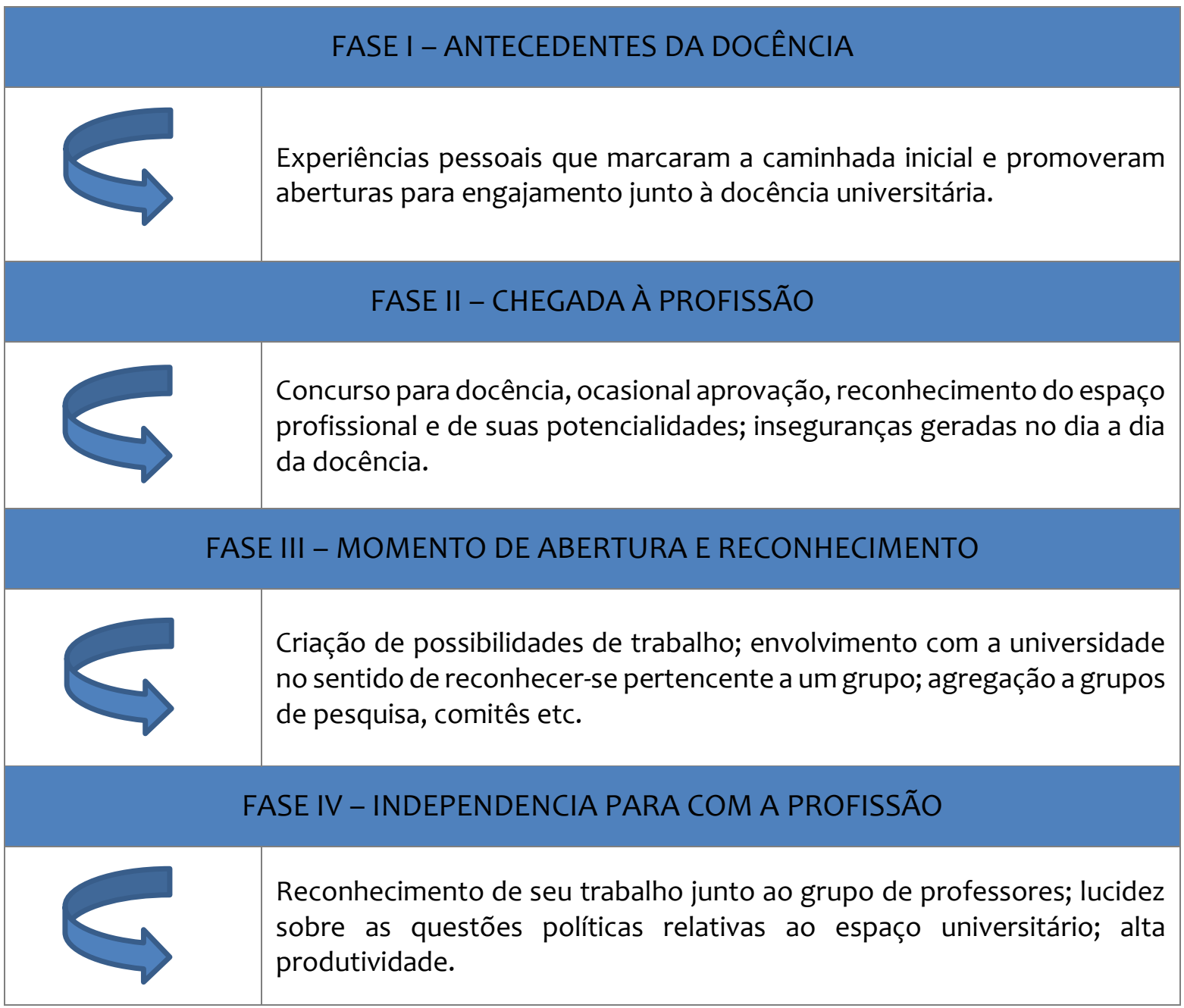

Fonte: Brito (2011), adaptado pelas autoras.

A segunda contribuição faz referência ao final aberto entre as etapas. Para Brito (2011) esse é o desafio de quem estuda o ciclo de vida profissional docente, ou seja, compreender que existe uma abertura entre as etapas; que existe a possibilidade de vivenciar, ao mesmo tempo, características de etapas diferentes; de estar em um tempo avançado da carreira, vivenciando sentimentos e desafios comuns de quem está no início. Sobre esse percurso aberto, a autora sintetiza seu pensamento com uma síntese e uma imagem sobre como enxerga o processo de viver, por meio do qual, também, se apropria para pensar o ciclo de vida dos professores. Em sua análise:

[...] p processo do viver, sob o meu ponto de vista, é uma progressão geométrica: as pessoas crescem, sob suas crises de mudança de estrutura biológica, psíquica e social e os seus olhares sobre o mundo é o que modifica o grau de importância das coisas em suas vidas. Não vejo o processo de vida como parábola: crescente auge - decrescente. Vejo como um contínuo que vai sendo ampliado a cada momento de nossas vidas numa relação geométrica, como uma espécie de espiral (BRITO, 2011, p. 300) 
- Revista de Iniciação à Docência, v. 5, n. 1, 2020 -

Dossiê Temático: Docência Universitária: contribuições da pesquisa Publicação: maio, 2020 - ISSN 2525-4332

Para a autora, o ciclo de vida profissional pode ser representado por uma espécie de espiral aberto, demonstrando sua continuidade e ampliação - a cada momento do ciclo -, conforme ilustrado na Figura 1.

Figura 1 - Ciclo de vida humano x Ciclo de vida profissional.

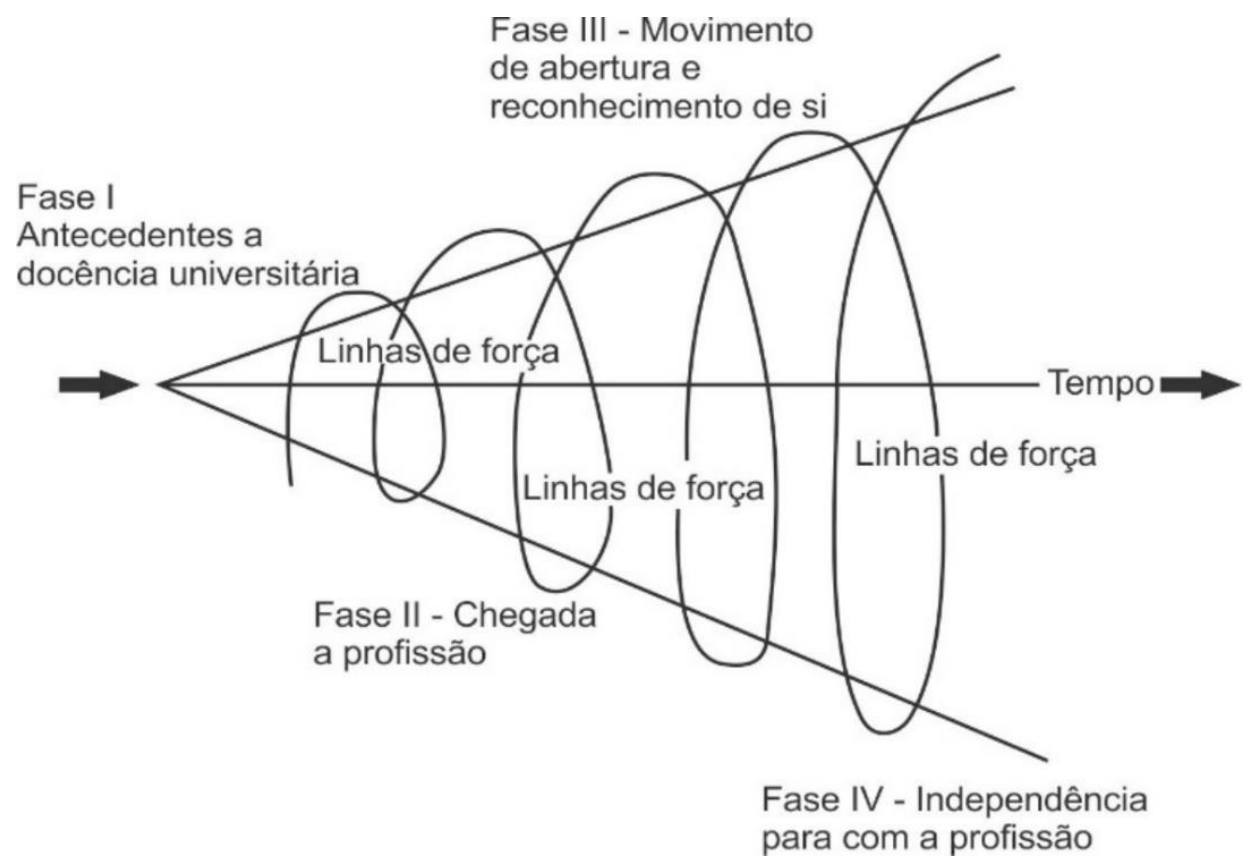

Fonte: Brito (2011), adaptado pelas autoras.

Para ela, a terceira contribuição se refere a Huberman (2000) - referência principal para estudar o Ciclo de vida profissional docente. No entanto, Brito (2011) ressalta que o estudo desse autor é elaborado a partir da realidade francesa - com base no ensino secundário -, ou seja, com professores que trabalham, apenas, com atividades de sala de aula. Também ressalta que o tempo de carreira de um professor secundário na França é de 40 anos, realidade diferente dos professores brasileiros. Essas observações apontam para a necessidade de se pesquisar o ciclo de vida profissional docente em outros segmentos do ensino a partir da realidade brasileira, considerando também as condições de trabalho dos professores e o meio social em que vivem. A partir dessas pesquisas, torna-se possível delinearmos um ciclo de vida profissional docente que contemple a realidade dos professores brasileiros (condições materiais do trabalho docente e condições subjetivas para escolher e permanecer na docência) e que considere os impactos políticos e econômicos sobre o trabalho do professor. Assim, teremos por base referências nacionais para nos reportarmos.

A quarta contribuição aponta para a observação de que os estudos de Huberman (2000) tiveram como orientação para os estudos aliados à aprendizagem na vida adulta e ao desenvolvimento profissional de professores, cuja percepção a respeito da vida é de um movimento de crescimento, estabilização e declive. Para Brito (2011), tanto o estudo de 
- Revista de Iniciação à Docência, v. 5, n. 1, 2020 -

Dossiê Temático: Docência Universitária: contribuições da pesquisa

Publicação: maio, 2020 - ISSN 2525-4332

Huberman, quanto os de outros autores - por exemplo, Riegel (1979) - seguem a orientação na qual a vida parece ter um momento de ápice, cuja ênfase está na vida adulta. Para Riegel (1979) tais relações, além de cíclicas, são decadentes e marcadas por fatores, tais como morte na família e aposentadoria. Assim, Brito (2011, p. 272) compreende a orientação desses autores como uma parábola, cuja síntese significa "[...] que temos um lugar na vida adulta de ascender, chegar ao topo/auge e depois decair. Um crescimento que por si só leva ao processo de declive [...]”. A autora sintetiza esse pensamento por meio da elaboração de um gráfico (Ver Figura 2), apresentando níveis em consonância com os anos (idade) dos professores.

Figura 2 - Ilustração elaborada por Brito (2011) sobre o Ciclo de Vida com base teórica. de Riegel (1979)

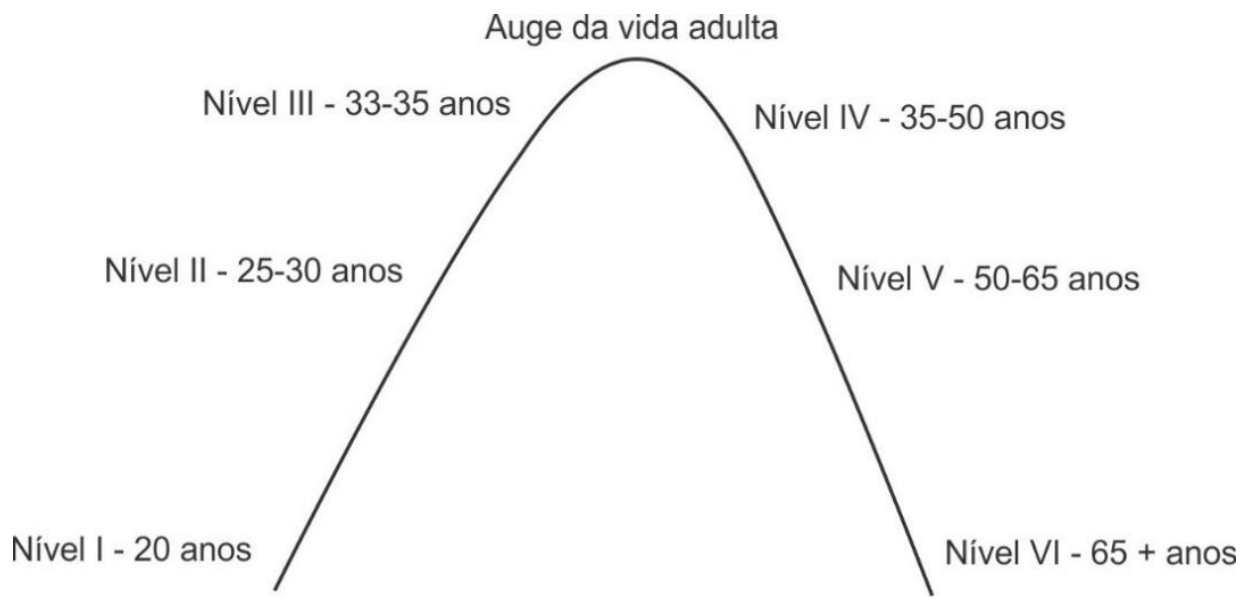

Fonte: Brito (2011), adaptado pelas autoras.

A constatação feita por Brito (2011) referente a esse movimento de parábola, no trabalho de Huberman (2000), indica a necessidade de olharmos o ciclo de vida profissional docente por um outro viés - mais amplo, mais aberto e que ultrapasse esse movimento marcado pelas etapas de início (busca), meio (estabilidade) e fim (reclusão). Essa reflexão faz referência ao fato de que podemos encontrar professores com significativo tempo de carreira, vivenciando o momento de ascensão; e professores em início de carreira, apresentando sinais de declive, ou seja, de desinvestimento ou até mesmo desistindo da docência.

\section{Considerações finais}

A realização do estudo do tipo estado do conhecimento nos proporcionou situar, aproximar e compreender o Ciclo de Vida Profissional Docente no Ensino Superior, a partir das pesquisas brasileiras e, também, compreender que existe um "ciclo" de vida profissional que acontece de forma individual e, ao mesmo tempo, coletivo para cada grupo de professores. Para compreendê-lo de forma abrangente e significativa, torna-se necessário considerar que existem "Linhas de Força" que atuam ao longo de toda 
- Revista de Iniciação à Docência, v. 5, n. 1, 2020 -

Dossiê Temático: Docência Universitária: contribuições da pesquisa

Publicação: maio, 2020 - ISSN 2525-4332

trajetória docente, orientando determinadas escolhas, certos relacionamentos e modos diferenciados de agir. E ainda que há um ciclo de vida profissional docente que perpassa pelas marcas do ensino superior somadas as concepções de docência trazidas de forma individual por cada professor e que cooptam uma docência técnica e interpessoal.

Esse estudo possibilitou, também, apontarmos que há carência expressiva de pesquisas sobre o ciclo de vida profissional docente, por meio dos quais sejam contempladas e consideradas as especificidades da formação e do trabalho docente no Brasil. Tais aspectos estão relacionados a carreira, tais como salário e plano de carreira; condições de trabalho, envolvendo discussões em torno da precarização e intensificação do trabalho docente; além de fatores e elementos implicados nas questões de ordem econômica, política e social. No geral, são aspectos que refletem as condições materiais e subjetivas da escolha por ser professor, estar e permanecer na profissão docente.

Outro apontamento diz respeito ao período do levantamento - uma década evidenciando que no cenário brasileiro há poucas referências para compor um rol de discussões diversificadas sobre essa temática. Observamos a presença de lacunas, com perspectivas para investigações futuras, apontando para a possibilidade de ser pesquisada com diversas categorias, tais como trabalho docente; gênero; raça; condições de trabalho; profissionalidade, dentre tantas outras que podem ser escolhidas e entrecruzadas.

Assim, consideramos que ao nos propormos compreender o ciclo de vida profissional docente - ao longo desse movimento progressivo -, torna-se importante criar uma rede que abarque, relacione e considere a história de vida de cada professor, evidenciando suas crenças; o meio social em que vive e trabalha; o contexto e a história da sua profissão; e a relação com os pares e os alunos. Ou seja, torna-se importante considerar os aspectos subjetivos e objetivos que perpassam suas vivências. Esses elementos, segundo julgamos, apontam que pode haver momentos de interseção e assim como Huberman (2000) poderemos apresentar em pesquisas futuras momentos que são apontados como linhas únicas. No entanto, as particularidades de cada professor, somadas as singularidades das instituições de ensino superior, poderão apresentar ramificações diversificadas. Defendemos que essas ramificações precisam ser consideradas, pois compreendemos que elas são essenciais em estudos futuros, cuja pauta não esteja, apenas, nas generalizações, mas também nas particularidades que marcam e evidenciam a identidade de um grupo de professores que atuam em determinado segmento de ensino e compartilham características em comum.

Para concluir essa reflexão, evidenciamos que o levantamento de trabalhos referente ao ciclo de vida profissional docente nos alertou sobre a importância de compreendermos as ações dos professores em seus processos formativos e de pensarmos que, em cada momento dessa trajetória, devemos considerar as particularidades, os sentimentos, os dilemas e os desafios que os professores vivenciam em seus diferentes contextos, haja vista que não há sequências universais, uma vez que devemos relacionar 
- Revista de Iniciação à Docência, v. 5, n. 1, 2020 -

Dossiê Temático: Docência Universitária: contribuições da pesquisa

Publicação: maio, 2020 - ISSN 2525-4332

os momentos da trajetória docente com o período histórico e considerar que há uma influência mútua entre o comportamento dos professores e a organização da docência universitária.

\section{Referências}

ANDRÉ, M. E. D. A. A produção acadêmica sobre formação de professores: um estudo comparativo das dissertações e teses defendidas nos anos 1990 e 2000. Formação Docente, Belo Horizonte/MG, v. 1, n. 1, 2009, p. 41-56.

CAVACO, M. H. Ser professor em Portugal. Lisboa: Editorial Teorema. 1993.

BRITO, T. T. R. O ciclo de vida profissional dos professores da Universidade Federal de Uberlândia: Trajetórias, Carreira e Trabalho no Instituto de Biologia. 2011. 345f. Tese (Doutorado em Educação) - Universidade Federal de Uberlândia, Uberlândia/MG, 2011.

DELGADO, L. de A. N. História Oral: memória, tempo, identidades. Belo Horizonte/MG: Autêntica, 2006.

HUBERMAN, M. O ciclo de vida profissional dos professores. In: NÓVOA, A. (Org.). Vidas de professores. 2. ed. Porto: Porto, 2000.

ISAIA, S. M. A.; BOLZAN, D. P. V.; GIORDANI, E. M. Movimentos construtivos da docência superior: delineando possíveis ciclos de vida profissional. Anais da $30^{\mathrm{a}}$ ANPED GT 08: Formação de Professores, 2007.

RIEGEL, K. Foundations of dialectical Psychology. New York: Academic Press, 1979

ROMANOWSKI, J. P.; ENS, R. T. As pesquisas denominadas do tipo "estado da arte" em educação. Revista Diálogo Educacional, v. 6, n. 19, p. 37-50, 2006. 